\title{
Educação Sexual no Ensino de Ciências
}

\author{
Sex Education in Science Education
}

\author{
Elisângela Lima Da Silva ${ }^{1}$, Silvana da Silva ${ }^{2}$, Raquel Martins Fernandes Mota ${ }^{3}$ \\ e Ricardo Douglas de Sousa ${ }^{4}$
}

\author{
${ }^{1}$ Graduada, Departamento, IFMT - Campus São Vicente, Jaciara, MT, Brasil \\ ${ }^{2}$ Graduada, Departamento, IFMT- Campus São Vicente, Jaciara, MT, Brasil \\ ${ }^{3}$ Doutora, Departamento de Educação, IFMT- Campus Bela Vista, Cuiabá, MT, Brasil \\ ${ }^{4}$ Mestre, IFMT- Campus São Vicente, Jaciara, MT, Brasil
}

\begin{abstract}
Resumo
Educação Sexual no Ensino de Ciências foi o tema escolhido para trabalhar em uma Escola Municipal de São Pedro da Cipa. O trabalho deuse início com a coordenadora e professor de ciências da Escola, que nos relatou que nesta escola o conteúdo relacionado à sexualidade era apresentado em forma de palestra. A partir do professor de ciências, houve-se o primeiro contato com os alunos do nono ano que envolvemos na intervenção. Inicialmente, realizamos um diálogo de vinte minutos com 16 (dezesseis) alunos, argumentando a educação sexual no ensino de ciências. Realizou-se a dinâmica da "caixinha sigilosa", que versava cada aluno fazer sua pergunta referente ao tema proposto. Após análise das perguntas e curiosidades apresentadas pelos alunos, realizou-se aula expositiva dialogada, discorrendo assuntos sobre transformações no corpo, órgão sexual interno masculino e feminino, menstruação, ejaculação, tipos de sexo, métodos contraceptivos, DST's, entre outros a fim de sanar as dúvidas apresentadas. Após esta aula, realizou-se socialização dialogando o assunto abordado. Em seguida, aplicou-se questionário avaliativo. Constatou-se no resultado do questionário que a aula expositiva dialogada contribuiu para abertura ao diálogo e o conhecimento em relação ao corpo e para auxiliar o professor construiu-se uma cartilha a partir das dúvidas apresentadas pelos alunos.
\end{abstract}

Palavras-chave: Adolescência. Educação sexual. Sexualidade

\begin{abstract}
Sex Education in Science Education was the theme we have chosen to work in a Municipal School of St. Peter Cipa. The work has been started with the coordinator and science teacher at the School, who told us that this school related content sexuality was presented as a lecture. From the science teacher, were forwarded to the ninth graders to which we engage in the intervention. Initially, we conducted a dialogue twenty minutes with sixteen (16) students, arguing in a person's sexuality to work in the classroom. We conducted the dynamics of "secret box", which dealt each student asking your question on sexuality. After examining the questions and curiosities presented by the students, we return to this school for performing dialogic lecture, discussing issues about changes in the body, male and female internal sex organ, menstruation, ejaculation, types of sex, contraception and STDs in order to address the questions presented. After this lecture, we conducted socialization in dialogue the subject matter. Then apply evaluative questionnaire to ascertain. We note that the results of the questionnaire dialogic lecture helped to open dialogue and knowledge regarding sexuality and to help the teacher build a primer from the doubts raised by the students.
\end{abstract}

Keywords: Teens. Sex education. Sexuality 


\section{Introdução}

A Educação Sexual é um dos temas transversais propostos nos Parâmetros Curriculares Nacionais do Ministério de Educação e Cultura. Entretanto, há sempre dificuldade quando o tema é trabalhado em sala de aula, estando cercada por inquietações e dúvidas próprias do adolescente, que passa por diversas transformações físicas na puberdade. Apesar de atualmente se falar muito de sexo, principalmente nos meios de comunicação, ele continua sendo um tema delicado, tanto na família, quanto na escola. Muitos pais, no convívio familiar sentem-se desconfortáveis para falar abertamente com seus filhos e dar-lhes uma orientação adequada.

O presente trabalho tem finalidade de apresentar as etapas da elaboração do TCC para curso de Licenciatura em Ciências da Natureza. Trata-se de uma revisão bibliográfica com artigos, Parâmetros Curriculares Nacionais ( $\mathrm{PCN}^{\prime}$ s) e livros didáticos referentes à educação sexual nas escolas, em busca de caminhos necessários que propiciem discussões necessárias para se trabalhar o assunto de maneira clara e natural com os adolescentes superando os tabus encontrados entre Professor e aluno.

Não apresentaremos uma solução, mas buscamos alternativas necessárias para se discutir em sala de aula os problemas relacionados ao tema, procurando a interação e participação dos alunos, podendo contribuir com a aprendizagem na tentativa de mostrar ao professor que é possível aplicar e trabalhar o conteúdo com os alunos, de forma dinâmica e animadora.

\section{Objetivos}

O Objetivo Geral é avaliar o conhecimento dos alunos do nono ano da Escola Gessy Antônio da Silva em relação à educação sexual e desenvolver uma aula modelo para a escola.

\subsection{Objetivos Específicos}

๑Diagnosticar dúvidas e curiosidades dos alunos em relação à Sexualidade,

ه) Construir conhecimento, ministrando aula expositiva;

๑Avaliar o conhecimento obtido após aula expositiva com aplicação de questionário;

๑Construção de Cartilha Pedagógica, para auxílio do Professor.

\section{Referencial Teórico}

Sabemos que a sexualidade faz parte da vida de todos os indivíduos, e independe da idade. Assim, a sociedade, cultura e acompanhamento familiar são indispensáveis para o bom desenvolvimento do indivíduo enquanto dotado de sexualidade. Muitas vezes esse acompanhamento é limitado, acarretando problemas não solucionados; seja por falta de informação ou busca de conhecimentos (NUNES e SILVA, 2000).

A família tem um papel importante no desenvolvimento de formação do sujeito para a vida social, sendo ela a primeira fonte de informações, cabe a ela assumir também as responsabilidades para com seus filhos, não delegando estas informações somente a outras instituições, como as escolas e igrejas, pois elas sozinhas não irão resolver a questão. $\mathrm{O}$ envolvimento da família e escola no processo de educação sexual dos adolescentes deve ser desfrutado de maneira saudável, sem medos e preconceitos, buscando o diálogo entre ambos e superar os tabus encontrados (GASPAR et alli, 2006).

Segundo os planos curriculares nacionais (BRASIL, 2001) o papel da escola é proporcionar um espaço de discussão e reflexão que irá auxiliar no processo de formação do indivíduo, sendo esta diferenciada da educação realizada pela família.

Portanto, é importante trabalhar esse tema com os adolescentes, seja na família, escola ou religião, sendo o diálogo fundamental, educando os adolescentes a se conhecerem. 


\subsection{Histórico da Educação Sexual nas Escolas}

A educação sexual no currículo escolar tem sido discutida desde o século XX, despertando o interesse entre médicos, professores e outros. A abordagem dispõe-se de sua importância junto às crianças, adolescentes e jovens, para prevenção de Doenças Sexualmente Transmissíveis, gravidez indesejada, defendendo uma educação sexual para higiene dos jovens, preparando sujeitos saudáveis e responsáveis (CÉSAR, 2009).

Em meados do ano de 1928, foi discutida a aprovação do Programa de Educação Sexual no Congresso Nacional para Educadores, para se trabalhar com crianças acima de onze anos, sendo alvo central nos Projetos de educação sexual (AQUINO e MARTELLI, 2012, p. 02).

Somente a partir do ano de 1930, que o colégio Batista do Rio de Janeiro, apresentou em seu currículo o ensino de evolução das espécies e Educação Sexual, tendo como caráter inicial a reprodução feminina e a partir do ano de 1935 que foram incluídas discussões e análises da reprodução masculina, tendo como idealizador o professor Stawiarski, que foi processado, resultando na sua demissão (GUIMARÃES, 1995).

Já nos anos de 40 e 50 não se tem conhecimentos de trabalhos realizados a educação sexual, sendo que nessa época a Igreja Católica repreendia assuntos em questão, possuindo total domínio ao sistema educacional, mas mesmo assim foram publicados livros referentes à educação sexual, mas dentro da moral católica enfatizando uma educação de responsabilidade paternal, mas também com intuito de responder questões de caráter biológico e reprodutiva, fomenta (GUIMARÃES, 1995).

Segundo Guimarães (1995), na década de 60 ainda surgiram várias tentativas para implantação de Educação Sexual nas escolas públicas e particulares, mas devido às mudanças políticas geradas pelo golpe militar de 64, esses programas tiveram que ser interrompidos, devido à repressão do moralismo vigente, isso porque a Igreja Católica ainda possuía domínio ao Sistema Educacional.

Guimarães (1995) nos afirma que entre 63 a 68 ocorreram várias tentativas de implantação da Educação Sexual nos currículos das escolas do estado de São Paulo, sendo criados programas experimentais, com intuito de prevenção e informação, programas estes que tiveram duração de três meses, havendo rejeição dos pais, mas mesmo assim, algumas escolas do Rio de Janeiro, adotaram a Educação Sexual em todas as séries, isso a partir de 1964, já outras escolas implantaram o en sino em 1968, mas causando fortes consequências, tais como exoneração da direção, suspensão de alguns professores e expulsão de alguns alunos.

De acordo com César (2009), somente a partir dos anos finais da década de 70 e anos 80 que a sociedade brasileira convive a reabertura política, havendo grandes mudanças políticas e sociais, como também no campo da sexualidade, constituindo novas maneiras de compreender a Educação Sexual.

Os Congressos Nacionais sobre Educação Sexual nas escolas de iniciativa privada ocorreram entre 1978 e 1979, podendo perceber o grande interesse dos profissionais da educação sobre o tema. Assim, as argumentações referentes à inclusão da orientação sexual no currículo das escolas se intensificaram massivamente, influenciados pelo risco de infecção do vírus HIV e o aumento de casos de gravidez não planejada entre as adolescentes (BRASIL, 2001). Tal interesse é notado ao observarmos que no ano de 1983, a Federação Brasileira de Ginecologia e Obstetrícia realizou o $1^{\text {o }}$ Encontro Nacional de Sexologia, tendo como objetivo o controle preventivo de Doenças Sexualmente Transmissíveis e a gravidez indesejada entre adolescentes e jovens (GUIMARÃES, 1995).

Apesar de a discussão ter iniciado na década de 20 do século passado e intensificado na década de 80, foi somente a partir dos anos 90 que houve efetivamente a inserção da Orientação Sexual como tema transversal nos Parâmetros Curriculares Nacionais-PCN's (BRASIL, 2001). A discussão sobre educação sexual no ambiente escolar se avivou com a elaboração dos PCN's em 1996, com destaque em seu volume 10, reservado à Orientação Sexual (BRASIL, 2001). A sexualidade no espaço escolar não se inscreve apenas em portas de banheiros, muros e paredes. Ela "invade" a escola por meio das atitudes dos alunos em sala de aula e da convivência social entre eles. Com a inclusão da Orientação Sexual nas escolas, a discussão de questões 
convivência social entre eles. Com a inclusão da Orientação Sexual nas escolas, a discussão de questões polêmicas e delicadas, como masturbação, iniciação sexual, o "ficar" e o namoro, homossexualidade, aborto, disfunções sexuais, prostituição e pornografia, dentro de uma perspectiva democrática e pluralista, em muito contribui para o bem-estar das crianças, dos adolescentes e dos jovens na vivência de sua sexualidade atual e futura (BRASIL, 1997, p. 292 e 3).

A inserção dessas diretrizes dos PCN's não objetivou a introdução de regras imutáveis para serem seguidas pelos docentes; mas ao contrario, apresentaram orientações gerais aos docentes sobre a forma como esses assuntos devem ser trabalhados. Assim, não apresenta nenhuma especificação com relação às abordagens, estratégias e recursos de ensino. Dessa forma, propõe uma educação sexual em que nas salas de aula sejam problematizadas e repensadas as "verdades" que são instituídas como válidas e normais pelos currículos oficiais.

Cabe ao docente agora trabalhar em sala de aula as questões relacionadas à sexualidade envolvendo metodologias e técnicas que melhorem o processo de aprendizagem, moralidade e ética, ligando a escola aos demais espaços da vida do estudante (JOCA, 2009).

Em discussão histórica da Educação Sexual, percebe-se que ocorreram momentos de conquistas e recuos, sendo suas concepções influenciadas pelo tempo, ou seja, pelas pessoas, espaço e pelo movimento da sociedade. Apesar de atualmente se falar muito de sexo, ele continua sendo muito delicado até nos dias de hoje.

\subsection{Educação Sexual nas Escolas: A necessidade de superar tabus}

De acordo com Beraldo (2003), falar de educação sexual nas escolas ainda gera grandes polêmicas, que se associam inconvenientes e impróprias, pois a comunicação sobre esses assuntos ainda continua sendo um grande tabu, até porque no convívio familiar, muitos pais sentem-se desconfortáveis para falar abertamente com seus filhos e dar-lhes uma orientação adequada.

Muitos jovens descrevem que não falam com os pais sobre sexualidade por vergonha e medo que os pais possam vir a desconfiar de uma suposta vida sexual precoce (Gaspar, 2006). Esse fato leva a outra pesquisa que descreve que alguns adolescentes preferem falar com professores ou profissionais da saúde sobre dúvidas relacionadas a doenças sexualmente transmissíveis (BARROSO, 2008)

Portanto, a escola quer queira ou não possui um papel muito importante para diminuir as conseqüências da falta de informação sobre educação sexual, pois as manifestações estão presentes, cabe ao Professor (a) problematizá-las, ou seja, questionar, dialogar elementos a sexualidade, contribuindo para o desenvolvimento humano (AQUINO e MARTELLI, 2012).

De acordo com Braga (2006), é necessário que haja um diálogo no ambiente escolar em que se desperte a curiosidade e principalmente o interesse dos alunos, em se conhecer, sem preconceitos, pois esses assuntos são trazidos para dentro da escola junto com cada indivíduo e é necessário o desenvolvimento de uma ação reflexiva e educativa ao se tratar do assunto em questão.

Aquino e Martelli (2012) nos afirmam que na escola, a convivência entre crianças possibilita diferentes aprendizagens, favorecendo socialização de crenças, comportamentos e culturas, dentre eles a sexualidade.

Diante desta abertura de interpretações sobre como se trabalhar o tema Quirino (2013) descreve que o professor precisa estar ciente que as questões referentes ao tema podem surgir em diferentes momentos para cada aluno ou grupo, e mesmo que o professor já tenha discutido o assunto em sala de aula, pode ser necessária sua retomada.

Sabemos que a escola não muda a sociedade, mas pode partilhar com segmentos sociais, democráticos, constituindo um espaço de reprodução e transformação de conhecimentos sendo necessário que se busque formas de se trabalhar as questões da sexualidade junto aos adolescentes (PCN's, 2001).

Para Gaspar et alli (2006) é necessário o envolvimento da família e da escola no processo de educação sexual dos adolescentes, propondo esclarecimentos para que os jovens desfrutem a sua sexualidade de maneira saudável e com responsabilidade. A escola sozinha não resolve a questão 
descreve Paula e Santos (2012), sendo necessário que a família faça sua parte, mostrando à criança as questões de valores morais que cabe somente a ela.

Diante de todas essas questões, pode-se observar que, apesar de atualmente se falar muito de sexo, principalmente nos meios de comunicação, ele continua sendo um tema delicado para se trabalhar em sala de aula, mas é necessário evitar os tabus e preconceitos que envolvem a vida sexual humana.

\section{Material e Métodos}

Este estudo foi realizado na Escola Municipal de Ensino fundamental Gessy Antônio da Silva, presente na cidade de São Pedro da Cipa - MT, com alunos do nono ano. A Escola Gessy Antônio da Silva, portadora do CNPJ № 04.536.018/0001-63, situada na Rua Floriano Peixoto, na cidade de São Pedro da Cipa, foi criada pela Lei Municipal 461/91 em 02 de abril de 1991 e reconhecida pela portaria 3277/92 pela SEDUC. Desde 1992, a Escola vem sendo mantida pela Secretaria Municipal de Educação e rege-se por princípios e normas estabelecidas no regimento da Escola aprovado em 06/11/2000. Resolução Normativa № 630/2008 - CEE/MT, Decreto № 135/2000. A Escola Municipal oferece o Ensino Fundamental da Pré-escola ao Nono ano, sendo alunos do Centro da cidade, Vila Érica e Zona Rural.

Escolhemos esta Escola, devido à localidade, por ser em nossa cidade e perto de nossas casas e também pelo contato que já possuíamos com a comunidade de professores. Escolhemos a turma do nono ano para realização do TCC 11 devido ao incentivo do professor da área de Ciências. Quando visitamos a referida escola o professor nos relatou da necessidade em orientar os alunos, pois os mesmos tinham curiosidades sobre o tema, apesar de terem visto de forma básica no oitavo ano através de palestra. Ainda segundo o professor os alunos não se sentiam à vontade ao falar do assunto com ele e nesta sala de aula, assim como em outras salas como o oitavo ano, havia casos de namoros. Assim como em todas as Escolas é necessário que a orientação sexual seja discutida e refletida em sala de aula entre professor e aluno, em busca de clareza e superação dos tabus encontrados, buscando alternativas necessárias para interação professor/aluno.

E para se falar de educação sexual, sendo pessoas que não eram do convívio escolar, os alunos poderiam interagir melhor e terem conhecimentos em relação as suas curiosidades.

Vale ressaltar que este trabalho de intervenção não foi aplicado com a turma do oitavo ano, por ter outra professora regente, que nos relatou que seria muito cedo para se falar de sexualidade com os mesmos.

Para elaboração do Trabalho de Conclusão de Curso (TCC 11), realizamos na referida escola, uma pesquisa qualitativa (LUDKE, 1986). Essa pesquisa compreendeu, inicialmente, uma conversa com a coordenadora pedagógica da escola e o professor regente na área de Ciências, visando levantar possibilidades metodológicas para o desenvolvimento da pesquisa; posteriormente, fez-se uma abordagem com os alunos sobre Sexualidade dentro do ambiente escolar.

Inicialmente, realizamos uma visita à turma do nono ano, constituída por 16 alunos, de ambos os sexos, no dia 28 de fevereiro de 2014. Durante a visita realizou-se um diálogo de 20 minutos, onde se abordou sobre educação sexual na adolescência. Escolhemos esta turma primeiramente pelo incentivo do professor regente, pois os mesmos já ouviram sobre o assunto, através de uma palestra pela enfermeira da Unidade de Saúde. Essa palestra dada pela enfermeira abordou sobre DST's e Gravidez e pela necessidade que os alunos apresentavam em se falar de sexualidade, pois os mesmos questionavam suas curiosidades com colegas de sala nos corredores da Escola, não resolvendo a questão.

Posteriormente ao diálogo, para continuidade da intervenção e melhor participação dos alunos, adotou-se o método caixa sigilosa descrito por Freguglia \& Fonseca (2009) com modificações. Tal método consistiu em uma dinâmica, intitulada "caixinha sigilosa", que constitui em cada aluno fazer sua pergunta sobre sexualidade através de "bilhetinhos sigilosos", sem que os mesmos se identificassem, onde tais bilhetes foram colocados na caixa sigilosa, sendo esta realizada com a presença do Professor regente da disciplina. 
A continuidade da intervenção prosseguiu-se, conforme combinado com professor da disciplina de Ciências, na data de 24 de março de 2014, com a elaboração do Plano de aula. O processo de elaboração do plano de aula contou com a colaboração também da coordenadora pedagógica da escola, ponderando apenas assuntos que seriam relevantes em sala, haja vista das piadinhas feitas pelos alunos. O plano de aula partiu da análise dos questionamentos presentes na caixa deixada para esse fim. A atividade que se seguiu foi uma aula expositiva dialogada, utilizando de recursos de multimídia, com projeção em slides, em sala de aula.

Ao término da exposição, a aula teve continuidade com uma socialização e interação dos alunos para sanar as dúvidas referentes à educação sexual.

Em seguida aplicamos um questionário avaliativo, composto de oito questões de múltipla escolha, com a finalidade de avaliar os conhecimentos adquiridos em cada pergunta aplicada e se após a aula expositiva os alunos puderam amenizar suas dúvidas sobre Sexualidade.

Para auxiliar o professor regente da disciplina de Ciências, para se trabalhar assuntos de sexualidade com outros alunos, elaboramos uma Cartilha para ficar a disposição da escola. Tal cartilha partiu das principais dúvidas que os alunos demonstraram a respeito do tema Sexualidade na Adolescência. Essas dúvidas foram colhidas através das perguntas feitas pelos alunos e demais assuntos abordados em sala de aula. A intenção é proporcionar maior clareza aos alunos e trazer segurança ao professor ao se trabalhar com os alunos sobre o tema.

\section{Resultados e Discussão}

A partir do diálogo com a coordenadora da escola e com o professor de ciências, observou-se que para se falar de educação sexual com os alunos, o professor de Ciências se sentia constrangido devido às piadinhas dos alunos. Então, a aula sobre Sexualidade nessa escola era desenvolvida em forma de palestra pela enfermeira padrão da Unidade de Saúde do município, mostrando os assuntos relacionados às DST's e Gravidez na adolescência. Mas mesmo assim, os alunos possuem muitas dúvidas e curiosidades sendo necessário educá-los nos assuntos sobre Sexualidade, pois muitos dos pais também não acompanham o desenvolvimento dos filhos e são despreparados para falar de Sexualidade com eles, Beraldo (2003). Ao falarmos com o professor ele nos incentivou a falar sobre o assunto de imediato.

Sabemos que falar de Sexualidade com adolescentes não é tarefa fácil, mas é necessário que o professor desenvolva estratégias para abordagem do assunto.

Durante a realização deste trabalho na Escola, podemos perceber a resistência dos alunos no primeiro momento, causando desconforto e vergonha dos mesmos para interagirem durante a aula. Alguns alunos aparentavam estar curiosos, pois em primeiro momento os mesmos conversavam baixinho entre os colegas de salas, com sorrisos, mas não tiveram abertura para o diálogo; talvez por medo de piadinhas dos colegas. Nas palavras de Braga (2009), é necessário que haja um diálogo no ambiente escolar, despertando a curiosidade e interesse dos alunos, desenvolvendo uma ação reflexiva e educativa.

Para o envolvimento dos alunos nesta dinâmica, tivemos que sair da sala de aula afim de que os mesmos se sentissem mais a vontade para poder participar da dinâmica da caixinha. Ficamos fora da sala em torno de vinte minutos, na espera da participação de todos, ficando os alunos com a presença somente do professor de Ciências. Havia-se o receio por parte deles, da descoberta dos autores das perguntas; o que vem ao encontro da discussão acima a respeito da dificuldade que os adolescentes possuem de falar sobre o assunto.

Retornarmos a sala de aula após os alunos colocarem suas perguntas na caixa sigilosa e explicamos que voltaríamos em outro momento, com realização de aula expositiva dialogada, elaborada a partir das perguntas redigidas pelos mesmos.

Abrindo a caixa sigilosa para análise das perguntas feitas pelos alunos, podemos perceber que muitas são as dúvidas e curiosidades dos adolescentes em relação à Sexualidade, principalmente na questão da primeira relação sexual e o uso de métodos contraceptivos. Mas podemos constatar também, que apenas um aluno relatou que falar de sexualidade é besteira, pois se sentem 
constrangidos em falar do tema e de acordo com Beraldo (2003), isso acontece devido à repressão dos pais e muitos são despreparados em falar do assunto com seus filhos e na maioria das vezes esses adolescentes ficam sem respostas para suas dúvidas podendo causar conflitos inesperados na busca de informações impróprias. Mas é necessário que a escola propicie aos alunos essa temática da sexualidade, preparando indivíduos responsáveis para a vida que o cerca.

O processo de elaboração de Plano de aula e aplicação da mesma em sala teve a contribuição do professor de Ciências e coordenadora da escola que forneceu o livro didático para elaboração da aula expositiva dialogada, pois o livro contém informações necessárias em relação à sexualidade que contribuiu para a elaboração do plano de aula.

Durante a realização da aula expositiva dialogada, percebeu-se que os alunos intensificaram a ansiedade e curiosidade quanto às respostas às perguntas por eles realizadas. Percebeu-se ainda, que eles estavam mais soltos, o que possibilitou um diálogo e discussão com os mesmos. Esse fato do diálogo em sala de aula vem ao encontro com Braga (2006), que relata a necessidade do diálogo no ambiente escolar, para que se desperte a curiosidade e interesse dos alunos em se conhecer sobre o assunto.

No início da aula foi apresentado os assuntos a serem abordados referentes às perguntas e dúvidas dos alunos apresentados na caixinha sigilosa, sendo elas sobre menstruação, como se prevenir das DST's, métodos contraceptivos, gravidez e entre outras.

A inserção desses assuntos em sala fez com que alguns alunos se abrissem ao diálogo participando com perguntas e complementações, sendo uma dessas perguntas apresentadas por uma aluna que tinha curiosidade em saber se o corpo das meninas muda após a primeira relação sexual e se a mulher também tem orgasmo, entre outras; assim, começaram a interagir com a aula, não se preocupando com piadinhas, vergonhas ou constrangimentos. Sabemos que é necessário essa interação entre aluno e professor, pois a escola é um espaço que possibilita diferentes aprendizagens, favorecendo socialização de crenças, culturas e assuntos de Sexualidade, nos afirma Aquino e Martelli (2012).

Foi verificado que antes da aula, dezesseis alunos apresentavam dúvidas sobre sexualidade, após aula expositiva, com aplicação do questionário avaliativo, constatou-se que apenas três alunos (30\%) ainda apresentavam dúvidas. Isso leva a entender que é preciso que se adote formas metodológicas diferenciadas, envolvendo o aluno na participação das aulas propostas.

Em análise aos dados obtidos no questionário aplicado após aula expositiva dialogada, os alunos demonstraram um bom aproveitamento do conteúdo trabalhado em sala.

Em relação à primeira questão, com alternativa de verdadeira ou falsa que se refere à puberdade, 12 alunos (75\%) responderam corretamente e apenas 04 alunos (25\%) responderam incorretamente. Notou-se que os alunos estavam envolvidos na explicação do conteúdo abordado desde o início da aula apresentada.

Na segunda questão que versava sobre sistema reprodutor masculino assinalaram 06 alunos $(37,5)$ corretamente e 10 alunos (62,5) marcaram incorreto, percebeu-se que os alunos não obtiveram clareza, havendo confusão nas respostas entre testículos e escroto.

Na terceira questão que se abordou sobre as DST's, 14 alunos (87,5\%) obtiveram êxito em suas respostas e apenas 02 (12,5\%) não conseguiram responder corretamente. Nesta questão os alunos já tinham certos conhecimentos, pois já haviam visto o tema no oitavo ano apresentado em palestra.

Na quarta questão, que abordou também sobre o sistema reprodutor masculino, 12 alunos (75\%) responderam corretamente e 04 alunos (25\%) não conseguiram responder. Podemos perceber que nesta questão eles conseguiram assimilar a questão referente à questão 02 que se abordou sobre o sistema reprodutor e conseguiram entender melhor.

Na quinta questão que versou sobre menstruação, 09 alunos $(56,2 \%)$ responderam corretamente e 07 alunos (43,7\%) não souberam responder. Por ser uma sala composta de 09 meninos, percebeu-se que muitos deles desconhecem o assunto referente ao sistema reprodutor feminino.

$\mathrm{Na}$ sexta questão que fala sobre conhecimentos dos métodos contraceptivos, 10 alunos (62,5\%) apresentaram conhecimentos e 06 alunos $(37,5)$ desconhecem. Nesta questão, os alunos já tinham visto falar sobre os métodos contraceptivos. 
Na sétima questão, que versou sobre como esses alunos costumam esclarecer as dúvidas sobre sexualidade 05 alunos $(31,2 \%)$ responderam que esclarecem com amigos, 02 alunos $(12,5)$ procuram a família, 06 alunos $(37,5)$ usam a internet e 03 alunos $(18,7 \%)$ procuram os profissionais da saúde. Nesta questão percebeu-se que dos 16 alunos participantes da intervenção, nenhum assinalou que procura esclarecer suas dúvidas com o professor, isso nos leva a compreender que ainda existe esse grande bloqueio entre professor e aluno sendo necessário que se adote de formas metodológicas no intuito de buscar o diálogo entre professor e aluno.

$\mathrm{Na}$ oitava e última questão que versou sobre a aula apresentada para os mesmos, se contribuiu para tais esclarecimentos, 11 alunos $(68,7 \%)$ responderam que sim, 02 alunos $(12,5 \%)$ responderam que não e 03 alunos (18,7\%) que apenas em parte.

Ao final do trabalho foi apresentada uma cartilha para o Professor de Ciências, para auxiliá-lo nos conteúdos relacionados à Sexualidade. Essa cartilha aborda questões relacionadas ao desenvolvimento do corpo feminino e masculino, DST's, gravidez, menstruação, os tipos de preservativos, tipos de sexo, entre outros.

\section{Considerações Finais}

Observou-se que ainda existe um grande tabu entre professor e aluno na abordagem do assunto da sexualidade e a metodologia utilizada na escola é apresentada em forma de palestra, ministrada por uma enfermeira da saúde, que enfatizou apenas sobre Doenças Sexualmente Transmissíveis (DSTs) e gravidez e os alunos não se sentem a vontade para fazer perguntas ou comentários, devido às piadinhas feitas pelos colegas.

Ainda existe um longo caminho a ser percorrido, para poder superar as necessidades de aprendizado dos alunos, de forma clara e atualizada, portanto, há uma necessidade de se buscar meios pedagógicos para explorar melhor o assunto. Mas só a escola não resolverá o problema, é necessário o envolvimento da família para que assim os adolescentes falem da sexualidade de uma forma natural, sem preconceitos, sem receios e vergonha (PAULA e SANTOS, 2012).

É necessário que o Professor aborde esses assuntos em sala de aula e em qualquer momento que precisar, para atender as necessidades dos alunos, não se tornando um desafio a ser traçado.

Este trabalho foi relevante para nossa formação, pois como futuros docentes, também iremos nos deparar com essas situações em sala de aula. Para isso é necessário que adotemos diversas formas metodológicas reflexivas, para que haja questionamentos e interação dos alunos, relacionando os conteúdos com o seu dia a dia.

O professor de Ciências deve enriquecer seu planejamento com aulas diferenciadas, tornando-as prazerosas, despertando a curiosidade e interação dos alunos. É necessário também que toda equipe de professores contribua nesse processo de evolução dos adolescentes, não passando a responsabilidade somente para o professor da área de Ciências, sendo que em todas as disciplinas se podem falar e orientar os alunos quanto a sua sexualidade.

O professor também pode trabalhar o tema em parceria com a Unidade de Saúde, que por sua vez irá auxiliar nos quesitos de informativos referentes à saúde.

\section{Agradecimentos}

À Coordenação de Aperfeiçoamento de Pessoal de Nível Superior (CAPES) pelo subsídio através do Programa de Consolidação das Licenciaturas (PRODOCENCIA) Edital 019/2013, processo № 113.657, e do Programa Institucional de Bolsa de Iniciação à Docência (PIBID) Edital № 061/2013, processo № 128.570, IFMT/Campus São Vicente/Sub Projeto Ciências. 


\section{Referências}

AQUINO, Camila, MARTELLI, Andréia Cristina. Escola e educação Sexual: uma relação necessária. Seminário de pesquisa em educação da região sul. Unoeste, 2012.

BERALDO, Flávia Nunes de Moraes. Sugestões práticas: sexualidade e escola: um espaço de intervenção. Psicóloga da Universidade São Francisco e docente da Unifenas, 2000.

BRAGA, Eliane Rose Maio. Sexualidade infantil: a importância da formação de professores (as) na questão de gênero. In: Educação no século XXI: Múltiplos desafios/ Sandra Regina Cassol Carbello, Sueli Ribeiro Comar (organizadoras). Maringá: Eduem, 2009.

BRASIL. Ministério da Educação. Secretaria de Educação Fundamental. Parâmetros Curriculares Nacionais: pluralidade cultural, orientação sexual. - 3. Ed. - Brasília: A Secretaria, 2001.

BARROSO, Maria Grasiela Teixeira. Dialogando com professores na escola sobre sexualidade e DST's. Universidade Federal do Ceará, 2008.

CÉSAR, Maria Rita de Assis. Lugar de Sexo é na Escola? Sexo, Sexualidade e Educação sexual. In: Sexualidade; Secretaria de Estado da Educação. Superintendência de Educação. Departamento de Diversidades. Núcleo de Gênero e Diversidade Sexual. Curitiba: SEED - Pr., 2009.

FREGUGLIA, J.; FONSECA, M. Mudanças na adolescência, 2009. Disponível em: $<$ http://goo.gl/09eWqA\&gt;. Acesso 20/10/2013.

GASPAR, T.; MATOS, M. G.; GONÇALVES, A.; FERREIRA, M.; LINHARES, F.. Comportamentos Sexuais, conhecimentos e atitudes face ao HIV / SIDA em adolescentes migrantes. Psicologia, Saúde \& Doenças, 7 (2), 299 - 316, 2006.

GUIMARÃES, Isaura. Educação Sexual na Escola: mito e realidade. Campinas, SP: Mercado de Letras, 1995.

JOCA, A. M. Educação escolarizada e diversidade sexual: problemas, conflitos e expectativa. In: COSTA, A. H. C.; JOCA, A. M.; LOIOLA, L. P. Desatando nós: fundamentos para a práxis educativa sobre gênero e diversidade Sexual. Fortaleza: Edições UFC, pp. 99-140, 2009.

LUDKE, Menga; ANDRÉ, Marli E. D. A. Pesquisa em Educação: Abordagens Qualitativas. São Paulo - SP: Pedagógica e Universitária, 1986.

NUNES, César Aparecido; SILVA, Edna. A educação sexual da criança. Campinas- SP: Autores Associados, 2000.

PAULA, Jaqueline Assis de, SANTOS, Lenir Medeiros dos. Sexualidade na escola: a necessidade de superar tabus. Formação Continuada. Lambarí d'Oeste-MT. Janeiro 2012.

QUIRINO, Josiane da Silva. Sexualidade na escola: encaminhamentos metodológicos na perspectiva dos professores de Ciências. 2013. Disponível em http://www.uel.br/pos/mecem/arquivos_pdf/QUIRINO_Josiane_dissertacao.pdf. Acesso 20/10/2013. 